\title{
Characterisation of the interaction of neuropilin-1 with heparin and a heparan sulfate mimetic library of heparin- derived sugars
}

Background. Neuropilin-1 (NRP-1) is a multidomain membrane protein with soluble isoforms interacting with a complex network of other membrane receptors, their respective ligands and heparan sulfate (HS). It is involved in the development of vasculature, neural patterning, immunological responses and pathological angiogenesis. Methods. We have characterised the binding of a Fc fusion of rat NRP-1 (Fc rNRP-1) and of a soluble isoform, corresponding to the first four extracellular domains of human NRP-1, shNRP-1, using optical biosensorbased binding assays with a library of heparin derivatives. Selective labelling of lysines protected upon heparin binding allowed their identification by mass spectrometry. Results. Fc rNRP-1 bound to heparin with high affinity $(2.5 \mathrm{nM})$ and fast $\mathrm{k}_{\mathrm{a}}\left(9.8 \times 10^{6} \mathrm{M}^{-1} \mathrm{~s}^{-1}\right)$.

Unusually, NRP-1 bound both highly sulfated and completely desulfated stretches of heparin and exhibited a complex pattern of preferences for chemically modified heparins possessing one or two sulfate groups, e.g., it bound heparin with just a 6-O sulfate group better than heparin with any two of $\mathrm{N}$-sulfate, 6-O sulfate and 2-O sulfate. Mass-spectrometry based mapping identified that, in addition to the expected the b1 domain, the a1, and c domains and the L2 linker were also involved in the interaction. In contrast, shNRP-1 bound heparin far more weakly. This could only be shown by affinity chromatography and by differential scanning fluorimetry. Discussion. The results suggest that the interaction of NRP-1 with HS is more complex than anticipated and involving a far greater extent of the protein than just the b1-b2 domains. NRP-1's preference for binding long saccharide structures suggests it has the potential to bind large segments of HS chains and so organise their local structure. In contrast, the four domain soluble isoform, shNRP-1 binds heparin weakly and so would be expected to diffuse away rapidly from the source cell. 
1 Characterisation of the interaction of neuropilin-1 with heparin and a heparan sulfate

2 mimetic library of heparin-derived sugars

3 Katarzyna A. Uniewicz ${ }^{\llbracket \S}$, Alessandro Ori ${ }^{\Uparrow \sharp}$ Yassir A. Ahmed, Edwin A. Yates and David G.

4 Fernig $^{1 \pi}$

5 " Department of Biochemistry, Institute of Integrative Biology, University of Liverpool, Liverpool 6 L69 7ZB, United Kingdom

$7 \quad{ }^{1}$ Corresponding author:

8 David G Fernig

9 Department of Biochemistry, Institute of Integrative Biology, University of Liverpool, Liverpool

10 L69 7ZB, United Kingdom

11 Email: dgfernig@liv.ac.uk

$12 \quad \mathrm{Tel}+441517954471$

$13 \S$ Current address: Qiagen GmbH, Qiagen Straße 1, 40724 Hilden, Germany

$14 \$$ Current address: EMBL Heidelberg, 69117 Heidelberg, Germany 


\section{Abstract}

16 Background. Neuropilin-1 (NRP-1) is a multidomain membrane protein with soluble isoforms interacting with a complex network of other membrane receptors, their respective ligands and heparan sulfate (HS). It is involved in the development of vasculature, neural patterning, immunological responses and pathological angiogenesis.

Methods. We have characterised the binding of a Fc fusion of rat NRP-1 (Fc rNRP-1) and of a soluble isoform, corresponding to the first four extracellular domains of human NRP-1, shNRP-1, using optical biosensor-based binding assays with a library of heparin derivatives. Selective labelling of lysines protected upon heparin binding allowed their identification by mass spectrometry.

Results. Fc rNRP-1 bound to heparin with high affinity $(2.5 \mathrm{nM})$ and fast $\mathrm{k}_{\mathrm{a}}\left(9.8 \times 10^{6} \mathrm{M}^{-1} \mathrm{~s}^{-1}\right)$.

Unusually, NRP-1 bound both highly sulfated and completely desulfated stretches of heparin and exhibited a complex pattern of preferences for chemically modified heparins possessing one or two sulfate groups, e.g., it bound heparin with just a 6-O sulfate group better than heparin with any two of N-sulfate, 6-O sulfate and 2-O sulfate. Mass-spectrometry based mapping identified that, in addition to the expected the b1 domain, the a1, and c domains and the L2 linker were also involved in the interaction. In contrast, shNRP-1 bound heparin far more weakly. This could only be shown by affinity chromatography and by differential scanning fluorimetry.

33 Discussion. The results suggest that the interaction of NRP-1 with HS is more complex than anticipated and involving a far greater extent of the protein than just the b1-b2 domains. NRP-1's preference for binding long saccharide structures suggests it has the potential to bind large segments of HS chains and so organise their local structure. In contrast, the four domain soluble isoform, shNRP-1 binds heparin weakly and so would be expected to diffuse away rapidly from the source cell. 
Neuropilin-1 (NRP-1, reviewed (Uniewicz \& Fernig 2008)), was first described in 1987 as antigen A5 expressed by neural cells of Xenopus tadpoles, with a role as a neuronal recognition molecule regulating neural path finding and cell differentiation. Subsequently, it was shown to play an important role in physiological and pathological angiogenesis (reviewed in (Staton et al. 2007)). NRP-1 has since been implicated in a wide range of functions ranging from immunological responses (Bruder et al. 2004), to cell adhesion through interaction with integrins (Fukasawa et al. 2007; Valdembri et al. 2009). NRP-1 is suggested to effect such varied cellular responses by virtue of its interactions with a wide range of functional partners. Soluble ligands include vascular endothelial growth factors (VEGF) (Makinen et al. 1999; Soker et al. 1997; Soker et al. 1998), fibroblast growth factors and hepatocyte growth factor/scatter factor (HGF/SF) (West et al. 2005) while receptors include those for VEGF (Fuh et al. 2000; Whitaker et al. 2001) and for HGF/SF (MET) (Matsushita et al. 2007). Moreover, NRP-1 can also interact with itself (Giger et al. 1998; Nakamura et al. 1998; West et al. 2005) and, as an added complexity, many of the protein partners of NRP-1 also bind HS (West et al. 2005) (reviewed (Ori et al. 2008)).

HS is a heterogeneous, polydisperse polysaccharide composed of repeating disaccharide units, comprising 1,4 linked uronic acid ( $\square$-L-iduronate, IdoA, or $\square$-D-glucuronate, GlcA) and $\square$-Dglucosamine $(\mathrm{GlcN})$ with varying patterns of 2-O-sulfate in the former and 3-O-, 6-O-sulfate and $\mathrm{N}$-sulfate or $\mathrm{N}$-acetyl in the latter (reviewed (Ori et al. 2008)). HS also exhibits a domain structure, consisting of longer stretches of low sulfated disaccharide repeats, rich in D-GlcA (termed NA-domains), interspersed with shorter, more sulphated regions, in which higher levels of N-sulfated glucosamine and L-iduronate residues are found (termed S-domains) (Murphy et al. 2004). HS is a component of HS proteoglycans (HSPGs) present in the cellular membrane together with NRP-1, however, it is often substituted with heparin, its more fully sulfated experimental proxy, which is available in large quantities, owing to its role as a major anticoagulant therapeutic and resembles more closely, although is not identical to, the S-domains of HS.

X-ray crystallography has shown that NRP-1 interacts with heparin through the b1b2 domain, a region directly adjacent to the VEGF-A ${ }_{165}$ binding pocket (Appleton et al. 2007; Vander Kooi et al. 2007). NRP-1 has been proposed to dimerise in a heparin-dependent manner as a result of 
heparin and VEGF-A 165 binding (Vander Kooi et al. 2007). Thus, one model of the angiogenic functional complex of NRP-1 comprises VEGF-A $\mathrm{A}_{165}$ : NRP-1: heparin at a 2:2:2 ratio, and the complex formed in this way would further interact with VEGFR-2 (Vander Kooi et al. 2007). In vitro studies have suggested that the addition of heparin enhances the binding of VEGF-A $\mathrm{A}_{165}$ (Fuh et al. 2000; Gitay-Goren et al. 1992; Soker et al. 1996; Soker et al. 1998) and of placental growth factor-2 (Mamluk et al. 2002; Migdal et al. 1998) to NRP-1, and so elevate the number of binding sites for VEGF-A $\mathrm{A}_{165}$ in a NRP-1 dependent manner, without affecting the affinity between NRP-1 and VEGF-A ${ }_{165}$ (Soker et al. 1996; Whitaker et al. 2001). Moreover, binding of other growth factors, such as VEGF-C and VEGF-D, to NRP-1 appears to be fully dependent on the presence of heparin (Karpanen et al. 2006). However, other data point to a more complex relationship between these molecules. Thus, NRP-1 has been demonstrated to be a pure agonist of VEGFR2, indicating that it can stimulate angiogenesis independently of the VEGF-A ligand (Uniewicz et al. 2010a). Moreover, whereas heparin enhanced VEGF-A ${ }_{165}$ binding to NRP-1 and VEGFR-2, it also appeared to prevent NRP-1 interacting with VEGFR-1, suggesting a mechanism of functional competition that favours the formation of complexes of NRP-1 with VEGFR-1, or of NRP-1 with VEGFR-2, VEGF-A 165 and heparin (Fuh et al. 2000). An important issue is that the characterisation of the functional role of the interaction of NRP-1 with HS has hitherto been restricted to structural studies using constructs encompassing just the b1b2 domains. Thus, the current structural work may not provide sufficient information to interpret the biological investigations.

To bridge more effectively biological and structural investigations the interaction of NRP-1 with HS/heparin is characterised here in detail, at the level of recognition of polysaccharide structural features by the protein and of the sugar binding sites in the protein. A recombinant dimeric Fc fusion of rat NRP-1 (Fc rNRP-1) was used to examine the interaction with heparin and a series of heparin derivatives. Fc rNRP-1 bound to heparin with high affinity $(2.5 \mathrm{nM})$. The specificity of NRP-1 for structures in heparin were unusual. It interacted with both a persulfated and a fully desulfated heparin derivative. In stark contrast, human soluble monomeric NRP-1 (shNRP-1) exhibited much weaker interactions with heparin. The interactions of NRP-1 with heparin were further characterised using a "protect and label" approach (Ori et al. 2009). It was found that residues involved in heparin binding were present not just in the b1 domain, but also in the al and c domains, as well as in the L2 linker. 


\section{Experimental:}

102

103

104

105

106

107

108

109

110

111

112

113

114

115

116

117

118

119

120

121

122

123

124

125

126

127

128

129

\section{Materials}

Recombinant rat NRP-1 chimera (Fc rNRP-1), a soluble human truncated variant (shNRP-1) and human Fc were purchased from R\&D Systems (Abingdon, Oxon, UK). The same heparin (17 $\mathrm{kDa}$ average molecular weight) (Celsus Lab, Cincinnati, OH, USA) was used throughout, including for the production of the chemically modified polysaccharides (Table 1) and oligosaccharides of defined size. Heparin derivatives were as characterised previously (Yates et al. 1996) and heparin derived oligosaccharides were obtained from partial heparinase I (IBEX Technologies, Montreal, Canada) digestion of porcine heparin performed, as described previously (Popplewell et al. 2009; Powell et al. 2010).

\section{Preparation of biosensor surfaces}

Surfaces were prepared in an IAsys optical biosensor running IAsys plus software version 3.01. IAsys cuvettes functionalised with biotin (NeoSensors, Sedgefield, Cleveland, UK) were derivatised with streptavidin to enable subsequent capture of heparin that had been biotinylated at free amine groups (Rahmoune et al. 1998). Measurements were made at $20^{\circ} \mathrm{C}$ in a final volume of $50 \mu \mathrm{L}$, unless indicated otherwise. Briefly, biotin functionalised cuvettes were incubated for 40 minutes with $20 \mu \mathrm{L} 2.5 \mathrm{mg} / \mathrm{mL}$ streptavidin (Sigma-Aldrich, Gillingam, Kent, $\mathrm{UK}$ ) in $\mathrm{H}_{2} \mathrm{O}$ and $10 \mu \mathrm{L}$ of PBST ( $140 \mathrm{mM} \mathrm{NaCl}, 5 \mathrm{mM} \mathrm{NaH}_{2} \mathrm{PO}_{4}, 5 \mathrm{mM} \mathrm{Na}_{2} \mathrm{HPO}_{4}, 0.02 \%$ (v/v) Tween, $0.02 \%$ (w/v) sodium azide). After three washes in PBST the surface was incubated overnight at $4{ }^{\circ} \mathrm{C}$ with $20 \mu \mathrm{L}, 10 \mathrm{mg} / \mathrm{mL}$ biotinylated heparin. The resonance scan confirmed that the surface was modified uniformly. The Fc rNRP-1 and Fc alone were found, as before (West et al. 2005), not to bind detectably to streptavidin derivatised surfaces.

\section{Binding assays}

The initial binding tests and the measurement of dissociation were performed in a manually operated IAsys biosensor; association data were acquired in an IAsys Auto Plus instrument. In kinetic association assays, $5 \mu \mathrm{L} \mathrm{Fc} \mathrm{rNRP-1} \mathrm{was} \mathrm{injected} \mathrm{into} 45 \mu \mathrm{L}$ of PBST after a stable baseline was acquired. Association data were collected for $240 \mathrm{~s}$, after which the cuvette was washed with PBST and then regenerated by washing in $2 \mathrm{M} \mathrm{NaCl}$, before returning the cuvette to $45 \mu \mathrm{L}$ PBST for the following injection. Instrument noise was at most $\pm 0.5 \operatorname{arc} \mathrm{s}$. 
130 For dissociation assays, higher concentrations of Fc rNRP-1 were used, $1.2 \mu \mathrm{g} / \mathrm{mL}$ in $50 \mu \mathrm{L}$ of

131 PBST, and heparin was injected as a competitor to reduce the probability of re-binding (Sadir et

132 al. 1998). Following association and washing in PBST, dissociation was initiated by the injection

133 of $1 \mu \mathrm{L} 2 \mathrm{mg} / \mathrm{mL}$ heparin in PBST into the cuvette and followed for at least $60 \mathrm{~s}$. Regeneration of

134 the sensor surface was achieved as for the association assays with $2 \mathrm{M} \mathrm{NaCl}$.

135 In competition assays $40 \mu \mathrm{L}$ PBST and $5 \mu \mathrm{L}$ competing sugar were added to the cuvette and a

136 baseline was acquired. Fc rNRP-1 $(5 \mu \mathrm{L}, 5 \mu \mathrm{g} / \mathrm{mL})$ was then injected and association data

137 acquired for $300 \mathrm{~s}$. The cuvette was then washed in PBST and regenerated with $2 \mathrm{M} \mathrm{NaCl}$. As Fc

138 rNRP-1 seemed to lose its heparin-binding activity over time, no more than 25 binding curves

139 were collected from a single stock tube of the protein. At least two independent sets of data were

140 acquired for each sugar.

\section{Analysis of biosensor binding data}

142 Data analysis was done using the FastFit software version 2.03 (NeoSensors) provided with the 143 instrument. The validity of using a single site binding model to fit the data was established as 144 before (West et al. 2005; Xu et al. 2012). Briefly, to allow a single site model to be used, data 145 had to be randomly distributed around the model and in the case of association data, plots of the 146 slope of initial rate and of $\mathrm{k}_{\text {on }}$ against the concentration of NRP-1 had to be linear. The final

147 kinetic values and their respective standard errors (SE) were calculated from 5 independent 148 association experiments, and 6 independent dissociation experiments. In the figures, the response 149 prior to the injection of protein is set to 0 .

150 The competition assay data were normalised by comparison of extent of response of Fc rNRP-1

151 binding to the heparin surface versus the extent of Fc rNRP-1 response in the presence of sugar.

152 The control extent of binding was defined as $100 \%$, while values of Fc rNRP-1 binding in the 153 presence of inhibiting compounds were calculated as percentages relative to this value. The $\mathrm{IC}_{50}$

154 values were calculated using Origin 8 (OriginLab Corporation, Northampton, MA, USA)

155 applying a non-linear curve fit.

156 Selective labelling and identification of the heparin-binding peptides derived from Fc 157 rNRP1

158 Mapping of the heparin-binding site was performed, as described previously (Ori et al. 2009), 159 with some modifications. Briefly, to $20 \mu \mathrm{L}$ of AF-heparin beads (Tosoh Biosciences $\mathrm{GmbH}$, 
160 Stuttgart, Germany) packed in a minitip column and equilibrated in buffer A (17.6 $\mathrm{mM} \mathrm{Na}_{2} \mathrm{HPO}_{4}$,

$1612.6 \mathrm{mM} \mathrm{NaH}_{2} \mathrm{PO}_{4}, 100 \mathrm{mM} \mathrm{NaCl}, \mathrm{pH}$ 7.6, $0.02 \%$ (v/v) Tween 20), $4 \mu \mathrm{g}$ of Fc rNRP-1 was added

162 in a total volume of $80 \mu \mathrm{L}$ buffer A. The loading was repeated three times. After the column was

163 washed with buffer A, amino groups not protected by the interaction with heparin were acetylated

164 by the addition of $50 \mathrm{mM}$ sulfo-NHS-acetate (Thermo, Pierce, Perbio Science, Cramlington,

165 Northumberland, UK) in buffer B (18.3 $\left.\mathrm{mM} \mathrm{Na}_{2} \mathrm{HPO}_{4}, 1.7 \mathrm{mM} \mathrm{NaH}_{2} \mathrm{PO}_{4}, \mathrm{pH} 7.8\right)$ for 5 min. The

166 reaction was stopped by washing the column with buffer B. Acetylated proteins bound to the

167 column were eluted with $2 \mathrm{M} \mathrm{NaCl}$ buffered with $45.75 \mathrm{mM} \mathrm{Na}_{2} \mathrm{HPO}_{4}, 4.25 \mathrm{mM} \mathrm{NaH}_{2} \mathrm{PO}_{4}, \mathrm{pH}$

168 7.8. The eluate was exchanged into this buffer (45.75 $\mathrm{mM} \mathrm{Na}_{2} \mathrm{HPO}_{4}, 4.25 \mathrm{mM} \mathrm{NaH}_{2} \mathrm{PO}_{4}, \mathrm{pH}$ 7.8)

169 using a Vivaspin 100 kDa molecular weight cut-off centrifugal filter (Sartorius Stedim, Epsom,

170 Surrey, UK) blocked previously with BSA to avoid Fe rNRP1 nonspecific binding to the filter.

171 Subsequently, the lysines that were protected by heparin interaction were biotinylated using a

172 final concentration of $10 \mathrm{mM}$ NHS-biotin in dimethylsulfoxide (Thermo) and 30 min incubation

173 at room temperature. The reaction was quenched by the addition of Tris- $\mathrm{HCl} \mathrm{pH} 6.8$ to a final

174 concentration of $100 \mathrm{mM}$. Next, the sample was buffer-exchanged into $4.58 \mathrm{mM} \mathrm{Na}_{2} \mathrm{HPO}_{4}, 0.43$

$175 \mathrm{mM} \mathrm{NaH}_{2} \mathrm{PO}_{4}, \mathrm{pH} 7.8$ with a Vivaspin $100 \mathrm{kDa}$ molecular weight cut-off centrifugal filter and

176 dried by rotary evaporation.

177 The dried sample was dissolved in $8 \mathrm{M}$ urea, $400 \mathrm{mM} \mathrm{NH}_{4} \mathrm{HCO}_{3} \mathrm{pH} 7.8$ and digested with $1.5 \mu \mathrm{g}$

178 of chymotrypsin (Sigma-Aldrich), as previously described (Ori et al. 2009). Biotinylated peptides

179 were enriched using Strep-Tactin Sepharose (IBA, Stratech, Newmarket, Suffolk, UK) minitip

180 columns (Ori et al. 2009) and desalted using C18 ZipTip ${ }^{\mathrm{TM}}$ (Millipore, Watford, Herts, UK)

181 according to the manufacturer's instruction.

\section{Peptide analysis}

183 Desalted peptides were dissolved in $20 \mu \mathrm{l}$ of $0.1 \%(\mathrm{v} / \mathrm{v})$ formic acid in HPLC-grade water and

184 directly infused into a quadrupole-time of flight (Q-TOF) mass spectrometer (Waters

185 Corporation) at $0.2 \mu \mathrm{l} / \mathrm{min}$. The mass spectrometer was operated in the positive ion nano

186 electrospray mode with a source temperature of $80^{\circ} \mathrm{C}$ and capillary voltage $2.8 \mathrm{kV}$. First, a

187 survey scan was performed in MS-TOF mode in the range between 200 and 2,000 m/z. The most

188 intense ions were then manually selected and subjected to MS/MS analysis. For each ion the

189 MS/MS spectrum was acquired in the MS-Q-TOF mode. The precursor ion was selected in the

190 quadrupole, fragmented by collision-induced dissociation and then fragment ions were recorded 
by TOF (range: $80-3,000 \mathrm{~m} / \mathrm{z}$ ). The collision gas was argon and the collision energy was

192 manually adjusted during the acquisition between 25 and $45 \mathrm{~V}$. Peak lists were extracted using the

193 MaxEnt3 algorithm applying a $5 \%$ base peak intensity cut-off. Data analysis was performed

194 using the MS-tag tool of the Protein Prospector package v.5.2.2 (http://prospector2.ucsf.edu)

195 using the following parameters: digest = chymotrypsin; $\max$ missed cleavages $=5$; possible

196 modifications = acetyl (Lys), biotin (Lys), carbamidomethyl (Cys), carboxymethyl (Cys);

197 parental ion tolerance $=100 \mathrm{ppm}$; fragment ion tolerance $=300 \mathrm{ppm}$; non-specific cleavage $=$ at 1

198 termini. Both carbamidomethylation and carboxymethylation of cysteines were included as

199 variable modifications since S-carbamidomethyl-cysteine can be hydrolysed to S-carboxymethyl-

200 cysteine under the acid condition used for the elution of biotinylated peptides from Strep-Tactin

201 beads. The analysis was performed for monoisotopic ions with an error tolerance of $100 \mathrm{ppm}$ for

202 parental ions, and $300 \mathrm{ppm}$ for fragmented ions. The UniProt accession numbers of the proteins

203 analysed were used as a pre-search parameter. All other settings were used as default values.

\section{Homology modelling of human NRP-1}

205 The sequence of NRP-1 (Uniprot accession number O14786, residues 5-564) was homology206 modelled based on the 2QQM and 2QQK structures (Appleton et al. 2007), and the a1 and c domains modelled independently applying the same approach. The consistency of the secondary structures within the templates was verified by Dalilite (Holm \& Park 2000). The alignment was performed by Clustal W (Thompson et al. 1994) and its PIR presentation served to prepare the input file for Modeller (Eswar et al. 2008). Subsequent modelling produced five initial structures, which were verified by DOPE score in Modeller 9v7, and the lowest score model (most energetically favoured) was further optimised. In order to do so, the Ramachandran plot of the

213 chosen model was examined, and residues in the outlier region were remodelled to obtain correct 214 biophysical properties. Again, the best model was validated by the DOPE score, and additionally inspected by Model Quality Assessment Suite, and compared with the template structural files.

216 This showed that the obtained model was of medium quality, however, at the same time it did not

217 differ substantially in its properties from the input templates and it had no major structural

218 constraints. The final model was used to visualise the peptides identified in the selective labelling

219 experiment. Alignments were performed by Clustal W (Thompson et al. 1994) and served to

220 reflect best fitting of the identified peptides on the available crystal structure. In order to present

221 location of the identified biotinylated peptides of rat NRP-1, the homology-modelled human

222 NRP-1 was used. Subsequently, Pymol was used to illustrate these regions. 


\section{Dual polarisation interferometry (DPI)}

224 DPI analysis was performed on an AnaLight Bio200 System (Farfield Scientific, Manchester,

225 UK). The experiment was performed as described previously (Popplewell et al. 2009). Briefly, a

226 thiol chip was derivatized at $30^{\circ} \mathrm{C}$ with $5 \mathrm{mg} / \mathrm{mL} \mathrm{N}$-( $\square$-maleimidopropionic acid) hydrazide

227 (BMPH) (Thermo) applied at $8 \mu \mathrm{L} / \mathrm{min}$ to each flow cell to produce a surface with hydrazide

228 groups. Following washing with PBS at $50 \mu \mathrm{L} / \mathrm{min}$, the flow cell destined to be modified with

229 oligosaccharide was injected with $180 \mu \mathrm{L}$ of $2 \mathrm{mg} / \mathrm{mL}$ heparin-derived hexadecasaccharide (dp

230 16) dissolved in PBS pH 5 at $2 \mu \mathrm{L} / \mathrm{min}$. Subsequently, both flow cells were reacted with

231 aldehyde-functionalised poly(ethylene glycol) (PEG-CHO, $750 \mathrm{Da}$ ) (Rapp Polymere, Tübingen,

232 Germany) to block unreacted hydrazide groups. PEG-CHO $(180 \mu \mathrm{L}$ of $20 \mathrm{mg} / \mathrm{mL})$ dissolved in

233 PBS was applied at $1 \mu \mathrm{L} / \min$ and flow was stopped to allow an overnight incubation. The

234 injection of PEG-CHO was then repeated. After extensive PBS washes the temperature was

235 returned to $20^{\circ} \mathrm{C}$ and the surface was washed with $2 \mathrm{M} \mathrm{NaCl}$ in $10 \mathrm{mM} \mathrm{NaH}_{2} \mathrm{PO}_{4} \mathrm{pH}$ 7.5.

236 For binding assays proteins were added at $3.33 \mu \mathrm{g} / \mathrm{mL}$ (14 nM Fc NRP-1, $47 \mathrm{nM} \mathrm{hNRP}-1$ and

237123 control $\mathrm{Fc}$ ) at $50 \mu \mathrm{L} / \mathrm{min}$. After each binding assay, sensor surfaces were regenerated by a 30

$238 \mathrm{~s}$ wash with $20 \mathrm{mM} \mathrm{HCl}$ at $50 \mu \mathrm{L} / \mathrm{min}$ and then returned to PBS.

\section{DPI data analysis}

240 The derivatization of the surface and the subsequent protein-binding reactions were analysed with

241 Analight Explorer according to the manufacturer's instructions. The mass readings of the binding

242 are from the baseline prior to injection of protein, which was set to 0.

\section{Differential Scanning Fluorimetry (DSF)}

244 DSF was performed as described previously (Uniewicz et al. 2010b). Briefly, $0.57 \mu \mathrm{M}(136 \mu \mathrm{g} /$

$245 \mathrm{~mL})$ Fc rNRP1 was tested alone or with $1.132 \mu \mathrm{M}(19 \mu \mathrm{g} / \mathrm{mL})$ heparin or $11.32 \mu \mathrm{M}(190 \mu \mathrm{g} /$

$246 \mathrm{~mL}$ ) heparin, to give 1:2 and 1:20 molar ratios of dimeric Fc rNRP1 to heparin, respectively.

247 Similarly, a final concentration of $1.132 \mu \mathrm{M}$ shNRP1 was tested with $1.132 \mu \mathrm{M}$ heparin or 11.32

$248 \mu \mathrm{M}$ heparin (1:1 and 1:10 monomeric truncated shNRP1 to heparin, respectively). The assay was

249 performed in 96-well Reaction Plates (Applied Biosystems, Warrington, Cheshire, UK). The final

250 volume $(25 \mu \mathrm{L})$ comprised the protein dissolved in PBS $(20 \% \mathrm{v} / \mathrm{v})$, heparin dissolved in HPLC

251 grade water $(10 \% \mathrm{v} / \mathrm{v})$, PBS $(60 \% \mathrm{v} / \mathrm{v}$ or $70 \% \mathrm{v} / \mathrm{v}$ in case of the condition without heparin) and

252 a freshly prepared $100 \mathrm{x}$ water based dilution of Sypro Orange $5000 \mathrm{x}$ (Invitrogen) (10 \% v/v), 
253 added in the given order. During the additions, the plate was kept on ice and immediately

254 afterwards it was sealed with Optical Adhesive Film (Applied Biosystems) and directly analysed

255 in a 7500 Fast Real Time PCR System (software version 1.4.0) (Applied Biosystems) instrument.

256 The heating cycle comprised a $120 \mathrm{~s}$ pre-warming step to $31^{\circ} \mathrm{C}$ and a subsequent gradient

257 between 32 and $81{ }^{\circ} \mathrm{C}$ obtained in 99 steps of $20 \mathrm{~s}$, each of $0.5^{\circ} \mathrm{C}$. Data were collected using the

258 calibration setting for TAMRA ${ }^{\mathrm{TM}}$ dye detection ( $\square$ ex $560 \mathrm{~nm}$; $\square$ em $582 \mathrm{~nm}$ ) installed on the

259 instrument (as compared to Sypro Orange ideal settings $\square$ ex $492 \mathrm{~nm}$; $\square$ em $610 \mathrm{~nm}$ ). The data

260 were analysed using the Plot v. 0.997 software for Mac OS X by application of an exponential

261 correlation function approximation of the first derivative for each melting curve. 


\section{Results and Discussion}

263 The commercially available NRP-1 used in this study, Fc rNRP-1, encompasses most of the 264 extracellular part of the native protein with the omission of amino acid residues 811-828. The 265 entire C-terminal transmembrane/ intracellular region is absent. The protein is a chimeric 266 molecule, in which the rat NRP-1 sequence is fused to a Xa factor cleavage site, followed by the

267 Fc part of human IgG1 sequence, where the latter has the ability to form disulfide bridges 268 between the Fc domains (Figs S1A, B). Consequently, the final protein is a dimer. Such an 269 approach, where proteins are expressed as dimers, is often chosen to increase the stability of the 270 final product. Consequently, excluding the small deletion, the assayed protein comprises most of 271 the extracellular sequence of NRP-1 and is a soluble dimer. The protein also possesses a C272 terminal hexahistidine tag.

273 Fc rNRP-1 is modified by N-glycosylation, as shown by the increased electrophoretic mobility 274 following treatment with N-glycanase (Fig. S1D); the Fc part of Fc rNRP-1 is also the subject of 275 N-glycosylation (Fig. S1D). Additionally, analysis under native conditions revealed that the 276 whole protein migrates as a large aggregate, substantially exceeding the estimated size of the 277 intact dimer (Fig. S1E). This observation is in accord with previously observed oligomerisation 278 of Fc rNRP-1 in gel filtration (West et al. 2005) and implies that the protein in solution is an 279 oligomer.

Characterisation of kinetics of the Fc rNRP-1 interaction with heparin by optical biosensor binding assays

282 The interaction of Fc rNRP-1 with heparin was analysed in an optical biosensor. Heparin is a polymeric ligand, possessing a range of binding sites and immobilisation of the heparin to the surface through streptavidin may result in steric hindrance of some of these sites. Thus, at higher concentrations of ligate, secondary binding sites can appear in the analysis (Fernig 2001). As a consequence, a concentration range of Fc rNRP-1 of 0.25-1.22 nM was used, as only within this range was the interaction characterised by a one-site binding model. This means that, as with all such analyses, it is the interaction of Fc rNRP-1 with a class of highest affinity sites within heparin that is being measured, not the average of all the potential binding sites in heparin.

290 Increasing concentrations of Fc rNRP-1 showed increasing extents of binding (Fig. 1A). Each concentration exhibited a one-site binding model, since the data were distributed randomly

292 around the model (Figs 1B-F). The initial rate of binding, defined by the binding of the Fc NRP- 
2931 within the first $15 \mathrm{~s}$ of its addition was shown to increase in a linear manner with increasing 294 concentration (Fig. 1G). This illustrated that the binding of Fc rNRP-1 to heparin was not limited

295 by mass transport or by steric hindrance (Edwards et al. 1995). The calculated on-rate $\left(\mathrm{k}_{\text {on }}\right)$ was

296 observed to increase linearly with the concentration of Fc rNRP-1, which again supported the use

297 of a one site model to analyse the data (Fig. $1 \mathrm{H}) . \mathrm{k}_{\text {diss, }}$, was measured directly in a separate set of

298 dissociation experiments, where the addition of competing heparin in solution was used to

299 prevent the re-binding of Fc rNRP-1 to the heparin surface, a common artefact in such surface

300 measurements (Sadir et al. 1998). $\mathrm{k}_{\mathrm{a}}$ was extremely fast, $9.8 \times 10^{6} \mathrm{M}^{-1} \mathrm{~s}^{-1}$ (Table 2). Of the protein-

301 GAG interactions that have been studied, only that of HGF/SF with dermatan sulfate has been

302 found to be faster (Lyon et al. 1998). With a $\mathrm{k}_{\mathrm{d}}$ of $0.025 \mathrm{~s}^{-1}$, the $\mathrm{Kd}$ of the interaction is of high

303 affinity $(2.5 \mathrm{nM})$. The measured $\mathrm{k}_{\mathrm{d}}$ is considerably faster than that calculated from the intercepts

304 of the plots of $\mathrm{a}_{\text {on }}$ versus concentration (Table 2). This reflects the absence of re-binding

305 artefacts owing to the use of competing heparin during the dissociation phase in the direct

306 measurements of $\mathrm{k}_{\mathrm{d}}$ and is one explanation why a previous study (Narazaki et al. 2008)

307 determined a slower $\mathrm{k}_{\mathrm{d}}$, similar to that derived here from the intercept. Alternatively, the use of

308 just the b1-b2 domain in the latter study may explain the slower $\mathrm{k}_{\mathrm{d}}$ (Narazaki et al. 2008). Clearly,

309 Fc rNRP-1 can be classified among the high affinity interacting partners of heparin, though it

310 must be stressed that this is a measurement for the highest affinity binding sites in the sugar and it

311 is likely that there will be many lower affinity sites.

\section{Analysis of the structural requirements of Fc rNRP-1 binding to heparin}

313 After characterisation of the kinetics of the interaction of Fc rNRP-1 with heparin, the next

314 question focused on the structural requirements of heparin that favour this interaction. Two

315 different parameters were examined, namely, the length of the heparin oligosaccharide and the

316 sulfation pattern of heparin. While the first of these describes the architectural attribute of the

317 best fitted structure within the binding site of the Fc rNRP-1, the latter may provide additional

318 functional information, as different sulfation patterns have distinct solution conformations and so

319 functional properties (Rudd et al. 2007).

320 The identification of the binding preferences was established in competition tests, where Fc

321 rNRP-1 was compelled to select between binding to the heparin immobilised on the sensor

322 surface and a heparin-derived compound present in solution. In this way, the capacity of the 
323 assayed compounds to compete for Fc rNRP-1 binding to the heparin surface can be compared

324 with the same capacity of heparin added to solution.

325 The analysis of the minimal length of oligosaccharide that can be accommodated by Fc rNRP-1

326 applied compounds defined by their degree of polymerisation (dp), where dp 2 is the minimal

327 repeating disaccharide unit of heparin. The range used in this study covered dp 2 - dp 26.

328 Oligosaccharides of dp 2 - dp 8 had very weak competing potency, however, starting from dp 16, 329 a substantial inhibition of binding of the protein to the surface was observed (Figs 2A, B and S2).

330 It is noteworthy that the largest oligosaccharide tested, dp 26, was still significantly less effective 331 than heparin (Figs 2A, B and S2), which corresponded to the difference in size between dp 26 332 and heparin (16 kDa, $\mathrm{dp} \mathrm{34).} \mathrm{Thus,} \mathrm{while} \mathrm{there} \mathrm{was} \mathrm{a} \mathrm{clear} \mathrm{correlation} \mathrm{between} \mathrm{the} \mathrm{size} \mathrm{of} \mathrm{an}$ 333 oligosaccharide and its binding capability, there would appear to be a more complex relation 334 between the interaction of Fc rNRP-1 and of heparin, as full inhibition could only be observed 335 with native heparin (Figs 2A, B and S2). This preference for heparin, which is polydisperse in 336 length and sulfation, may reflect the size of the sugar binding site in the Fc rNRP-1, which may 337 be increased by the dimeric structure of $\mathrm{Fc}$ fusion protein or the requirement for a structure for 338 the highest affinity binding that is more common in the longest chains of heparin.

339 Next, the potency of variously sulfated heparin derivatives was tested. The compounds were 340 chemically produced from native heparin and enable an evaluation of the importance of particular 341 patterns of sulfation for Fc rNRP-1 binding. Removal of one sulfate group from heparin (Table 1, 342 Figs $2 \mathrm{C}$, D; NAc, 2-OH, 6-OH) caused a substantial reduction in binding $\left(\mathrm{IC}_{50}\right.$ increased by 40 343 to 77-fold), with Fc NRP-1 showing a graded preference for heparin containing 2-O sulfate and $344 \mathrm{~N}$-sulfate groups over 6-O sulfate groups. Intriguingly, these preferences did not extend to 345 heparins lacking two of three sulfate groups. Thus, whilst heparin with just N-sulfate (2-OH, 6$346 \mathrm{OH})$ and 2-O sulfate $(\mathrm{NAc}, 6-\mathrm{OH})$ had $\mathrm{IC}_{50}$ values 65 - and 118-fold higher than native heparin, 347 respectively, heparin with just 6-O sulfate groups (NAc, 2-OH) had an $\mathrm{IC}_{50}$ lower than any of the 348 monodesulfated heparins (Figs 2c, d). Moreover, Fc NRP1 bound completely desulfated heparin 349 at least as well as the monodesulfated heparin and far better than heparin carrying just 2-O sulfate 350 or N-sulfate groups. However, persulfated heparin was the most effective competitor, with an $351 \mathrm{IC}_{50}$ lower than that of heparin.

352 These data indicate that the binding motif of Fc rNRP-1 in heparin is more complex than one 353 described by a simply linear sequence of sulfated sugar residues or by simple ion-exchange. 
354 Thus, it would seem that although ionic interactions are important, there are other interactions,

355 which allow a sugar structure to bind to Fc rNRP-1 quite effectively. Moreover, persulfation

356 places sulfate groups at the $\mathrm{C} 3$ position of glucosamine and it may be that this is an important

357 requirement for Fc rNRP-1 binding. This is intriguing, since 3-O sulfated structures are rare in

358 heparin and cellular HS (Lindahl et al. 1998).

359

360

Identification of the protected regions of Fc rNRP-1 upon interaction with heparin

361 A structural proteomics approach, termed "protect and label" (Ori et al. 2009), was used to

362 identify heparin binding sites in Fc rNRP-1. This method has been applied successfully to

363 identify heparin-binding sites in single domain proteins, such as a series of FGFs, platelet factor 4

364 and pleiotrophin (Ori et al. 2009; Xu et al. 2012). Here it was used for the first time to study a

365 multidomain protein, Fc rNRP-1.

366 In initial experiments, it was found that while Fc rNRP-1 bound the heparin column effectively, it 367 was released during the acetylation step. One explanation might be that, although Fc rNRP-1

368 binds large oligosaccharides with high affinity, the interaction might be quite dynamic at the 369 atomic level, such that the protein might "rock" on its polysaccharide-binding site(s). In the

370 presence of NHS acetate, as lysines involved in heparin binding became temporarily exposed

371 they would become acetylated and consequently not be able to re-bind the protein. Alternatively,

372 the reversal of charge on many exposed lysines not involved in heparin binding may alter the

373 conformation of the protein so that it binds heparin less effectively. This would be consistent with

374 the known effects of chemical modification of lysines in some proteins, namely structural

375 rearrangement (Nakagawa et al. 1972) and loss of stability (Fazili et al. 1993). Therefore, the

376 initial binding step was performed in PBS, but the subsequent acetylation step was done without

$377 \mathrm{NaCl}$, to prevent loss of Fc rNRP-1 (Fig. 3A).

378 This allowed the generation of 15 ions that were assigned to particular sequences (Table 3, Fig.

379 S5). Five other ions were not matched to any region of the recombinant Fc NRP-1, which might

380 be due to modifications (either posttranslational, e.g., glycosylation, or due to the experiment)

381 occurring, which were not accounted for. All assigned ions encompassed one biotinylated lysine

382 residue, and corresponded to the NRP-1 moiety of the fusion protein or the IgG1 Fc moiety

383 (Table 3). The peptides identified within NRP-1 moiety were mapped to the a1, b1, c domains 
384 and to the linker following the c domain (L2) (Table 3). Within the a1 domain two sequences

385 were identified based on three independent ions, whereas within the b1 domain one largely

386 overlapping sequence was identified by two independent ions. Within the c domain three

387 sequences were identified from one ion each, while the fragment within the L2 region was

388 identified by two independent ions (Table 3). In the IgG1 Fc part of the recombinant protein four

389 peptide sequences were identified, where one of them were based on two independent ions, and

390 the remaining three on one ion each. The list of peaks with assigned values is described in Fig.

391 S5.

392 These data identify part of the known heparin-binding region of NRP-1 in the b1-b2 domains

393 (Fig. 3, blue label, (Fig. S3) (Mamluk et al. 2002) and, importantly, extend heparin binding to the

394 a1, c domains and the L2 linker (Figs 3B, C and S3). The identification of regions within the

395 IgG1 Fc part of the recombinant protein was surprising, as in optical biosensor and DSF

396 measurements the IgG1 Fc did not interact with heparin or heparin-derived oligosaccharides

397 (Figs 4, 5 and (West et al. 2005)). This may be the consequence of Fc possessing weak heparin

398 binding sites ( $\sim \mathrm{mM}$ affinity), which only become apparent when it is placed in proximity to

399 heparin on the affinity column by virtue of the primary interaction ofNRP-1. Similar arguments

400 may contribute to the identification of lysine residues in the NRP-1 moiety outside the b1-b2

401 domains as interacting with heparin. Several lines of evidence support the argument that the

402 novel binding sites in rNRP-1 represent real sites of interaction. The main structural study of the

403 residues involved in heparin interaction is based only on the b1b2 domain construct (Vander Kooi

404 et al. 2007), so it could not predict other areas of interaction. Moreover, secondary binding sites,

405 which may be of lower affinity, as found in FGFs (Ori et al. 2009; Xu et al. 2012) may have been

406 overlooked in favour of a dominant high affinity site. Thus, the current model of the interaction

407 of NRP-1 with heparin describes specifically the interaction with the b1-b2 domains, but not the

408 whole protein, and so may lose the context of the additional domains present in NRP-1. Analysis

409 of the conservation of the lysines identified in Fc-rNRP-1 across vertebrates shows that most are

410 conserved (Fig. S3). In two cases (K22 and K 746) the zebrafish has a basic residue one amino

411 acid upstream and only for K832 in Fc-rNRP-1 is there no corresponding basic residue in

412 chicken, Xenopus laevis or zebrafish. The conservation of these residues is consistent with their

413 structural or functional importance, which may relate to their involvement in binding to HS.

414 To visualise the identified peptides on a 3-D structural model the most complete available

415 structures of NRP proteins were selected for the in silico modelling purpose. The structures of 
NRP proteins, 2QQM and 2QQK, cover only ala2b1b2 domains of NRP-1 and NRP-2 (Appleton et al. 2007). This region of the protein is followed by long unstructured elements, namely the L1 and L2 linkers, and the c domain, and to date no data are available on their possible conformation, as such regions are problematic for structural studies. Similarly, owing to the substantial size of these elements no in silico approach is capable of making a prediction of their conformation. The appropriate residues were highlighted within the modelled structure (Fig. 3C). Only five of the peptides identified in the Protect and Label experiment could be mapped on the available structure, and are indicated by 3 regions highlighted in green. Three of them mapped to the a1 domain, while other two were found to be in close proximity of the heparin-binding site in the b2 domain identified in other experiments, which is shown in blue (Vander Kooi et al. 2007). Unfortunately, the remaining five peptides were not covered by the structure, since they were localised in the c domain and L2 linker following the c domain.

\section{The interaction of shNRP-1 with heparin}

Given the differences found in the interaction of Fc rNRP-1 with heparin compared to that of the b1-b2 domain, we investigated the properties of shNRP-1 (Fig. S1). shNRP-1 covers the sequence of a naturally occurring alternatively spliced soluble human isoform of NRP-1 and corresponds to domains a1, a2, b1, b2, but lacks the L2 linker and the c domain (Fig. S1). Thus, it contains the b1-b2 domain that covers the hitherto established heparin binding site of NRP-1. shNRP-1 was found to be modified by N-glycosylation, though in contrast to Fc rNRP-1, in native PAGE conditions it appeared to migrate as a monomer (Fig. S1).

436 Surprisingly, initial experiments revealed that there was no detectable binding of shNRP-1 to heparin-derivatised surfaces in optical biosensor experiments (Fig. 4). Here, heparin was immobilised to the surface by means of biotin groups introduced to its free amino groups. It has previously been shown in the case of cyclophilin B, that such internal biotinylation can abrogate

440 the interaction of a protein with heparin (Vanpouille et al. 2007). To exclude the possibility that 441 biotinylation of heparin was interfering with shNRP-1 binding, a dp 16 was immobilised through

442 biotin at its reducing end onto the more sensitive dual polarisation interferometer (West et al.

443 2005). Again, the binding of shNRP-1 was not detectable (Fig. 4). However, shNRP-1 was

444 observed to bind to Toyopearl heparin resin, indicating that the protein probably does indeed bind 445 heparin. Although shNRP-1 bound to the heparin column, it was observed to consistently elute 
446 from the column during the post-acetylation wash steps, despite these being of low ionic strength

447 (Fig. S4), precluding any further analysis.

448 Overall, these data support the argument that shNRP-1 interacts with heparin much more weakly 449 than Fc NRP1 (this work) or the b1-b2 domains in isolation (Narazaki et al. 2008). To provide 450 further evidence for this interaction, the thermostabilisation of proteins that follows their binding 451 to heparin was exploited (Uniewicz et al. 2010b). To establish comparable conditions for the 452 analysis of recombinant NRP-1s, it was assumed that each NRP-1 moiety had the potential to 453 bind to one heparin molecule, therefore, whereas shNRP-1 was assayed at ratios of heparin of 1: 4541 and 1: 10, Fc rNRP-1 was assayed at 1:2 and 1:20. Both isoforms displayed higher melting 455 temperatures (Tm values) in the presence of heparin, which supported the capability of shNRP-1 456 to bind to heparin (Fig. 5). Again, the Fc part alone was confirmed to not interact with heparin 457 (Fig. 5).

Implications of the interactions of Fc rNRP-1 and shNRP-1 with heparin and the heparinderived sugar library

We have extended the characterisation of the interaction of NRP-1 with heparin/HS from just the b1b2 domain to the entire protein in two different contexts: as an Fc fusion, Fc rNRP-1 and as a monomer corresponding to a naturally occurring soluble isoform covering the first four extracellular domains, shNRP-1. There are clear physical differences in the two proteins. The Fc rNRP-1 fusion will be a dimer and this has a clear tendency self-associate into oligomers (Fig. S1 and (West et al. 2005)), whereas shNRP-1 remains a monomer (Fig. S1). A likely reason for the difference in the state of oligomerisation of the two proteins is the MAM type c domain and these are often found to drive protein-protein interactions (reviewed (Uniewicz \& Fernig 2008)). Thus, although there are no data to support this directly, it is possible that the c domain drives self-association of NRP-1 in the membrane, which would be enhanced by the reduced dimensionality afforded by this cellular location. Consequently, the Fc rNRP-1 fusion protein may in this respect be a reasonable model for membrane NRP-1.

472 Analysis of the interaction of Fc rNRP-1 with heparin identified some unusual features. The 473 interaction is of high affinity with a high association rate constant. In terms of binding sites in 474 the sugar, Fc rNRP-1 clearly has a preference for longer structures, alongside an ability to bind 475 both highly suflated and non-sulfated structures (Fig. 2). The identification of several distinct 476 sites of interaction in Fc NRP-1 in the protect and label experiments (Table 3) is consistent with 
477 the preference for long sequences of heparin. While it is possible that the peptides identified in

478 these experiments in the a1 and c domains and in the L2 linker were an artefact of the low ionic

479 strength required for the protection step, it should be noted that only a proportion of lysine

480 residues in Fc rNRP-1 were labelled. This argues that by binding Fc NRP-1 to heparin in PBS the

481 specificity of interactions was maintained and suggests that NRP-1 may indeed have multiple

482 heparin binding sites. Considering the size of NRP-1, this seems a reasonable interpretation, since 483 smaller, single domain proteins such as endostatin, RANTES (Sasaki et al. 1999; Shaw et al.

484 2004) and members of the FGF family (Ori et al. 2009; Xu et al. 2012) have well documented

485 multiple heparin binding sites. Morever, these sites seem to be conserved across evolution in the

486 case of the FGFs (Xu et al. 2012) and NRP-1 (Fig. S3). Given the large size of the most effective

487 heparin-derived binding structures and the observation that heparin and desulfated heparin bind

488 competitively, this further suggests that polysaccharides of different structure may engage

489 overlapping sites in the rFc NRP-1. However, it is not possible to distinguish protection of a

490 lysine residue by heparin from protection by an intramolecular interaction; that the latter may in

491 some instances be caused by conformational change/domain re-arrangement triggered by heparin

492 binding is clearly possible, since heparin bound Fc NRP-1 has a substantially increased melting

493 temperature (Fig. 5), indicative of structural change in the protein. Thus, which of the peptides

494 encompassing protected and labelled lysine residues are directly involved in heparin binding

495 remains to be established directly.

496 HS, which will be the physiological polysaccharide NRP-1 binds in the pericellular matrix of 497 cells, is less sulfated than heparin and it has a domain architecture (Murphy et al. 2004). Thus, in

498 HS sulfated tracts of saccharides (S-domains) are relatively short, flanked by transition domains

499 (NAS domains, lower sulfation with $\sim 1$ glucosamine in two N-sulfated), separated by non

500 sulfated NA domains of repeating disaccharides of glucuronic acid and N-acetyl glucosamine.

501 Although the interaction of Fc rNRP-1 with desulfated heparin suggests that it would bind the

502 NA domains, the disaccharide units of the latter contain glucuronic acid residues, whereas in

503 desulfated heparin iduronic acid will be the dominant uronic acid epimer. The flexibility of the

504 iduronate acid ring (Torri et al. 1985) is recognised to be important in protein binding (reviewed

505 (Ori et al. 2008)). Thus, the present data suggest two possible modes of binding of NRP-1 to HS.

506 In one, NRP-1 can interact with glucuronic acid containing disaccharides and the NRP-1 would,

507 therefore, be able to bind large units containing successive NA-NAS-S-NAS domains. The

508 alternative, in which NRP-1 binding requires iduronic acid residues, would entail NRP-1 binding 
509 a series of NAS-S-NAS units, with the NA domains forming loops away from the protein surface.

510 In either case, an important consequence is that NRP-1 has the potential to organise the structure

511 of large segments of HS chains in the pericellular matrix. This would be a new and important

512 function, since the spatial organisation of HS chains in the pericellular matrix has been suggested

513 to contribute to the control of the diffusion of morphogens and growth factors (Duchesne et al.

514 2012).

515 The interaction of shNRP-1 with heparin could only be detected by affinity chromatography and 516 DSF, suggesting that this interaction is weak. shNRP-1 was a monomer, in contrast to Fc NRP-1, 517 which readily oligomerises (Fig. S1 and (West et al. 2005)). With the c domain and L2 linker 518 heparin binding site lacking in shNRP-1, this suggests that these sites or the possible c-domain 519 dependent dimerisation/oligomerisation of NRP-1 may be an important mechanism for NPR-1 to 520 bind to heparin. Thus, the existence of two distinct soluble species of NRP-1 containing either all 521 extracellular domains (120 kDa) (Lu et al. 2009; Swendeman et al. 2008) or the four of shNRP-1 $522(75 \mathrm{kDa})(\mathrm{Xu}$ et al. 2008) may have distinct functions; the latter would not be retained on the HS 523 of the shedding cell's pericellular matrix. Differences between membrane bound and soluble,

524 shed species have been observed for other proteins, e.g., receptor for advanced glycation products 525 (RAGE) and endothelial cell protein C receptor (EPCR) (Koyama et al. 2007; Molina et al. 526 2008). Thus, the different heparin-binding properties of the dimerised/oligomeric NRP-1 and the 527 monomeric isoforms might drive distinct output responses of the cells.

\section{Conclusion}

529 The present work shows that the selectivity of NRP-1 for saccharide structures in HS is more 530 complex than found for other heparin-binding proteins. Moreover, NRP-1 potentially may 531 possess multiple heparin binding sites. While the direct interaction of the lysine residues

532 identified in the selective labelling experiments clearly needs corroboration by an orthogonal 533 approach, the potential for NPR-1 to possess multiple heparin binding sites is coherent with its 534 preference for binding long sugar structures. This suggests that NRP-1 may have an important 535 function in locally organising HS chains in the pericellular matrix of cells. The weak binding of 536 shNRP-1 supports the view that the b1-b2 domain is not representative of NRP-1's interaction 537 with HS and that an important functional difference between NRP-1 isoforms may relate to their 538 different ability to bind the polysaccharide.

\section{Acknowledgements}


540 The authors would like to thank Dr Jonathan Popplewell from NeoSensors for DPI technical

541 training and outstanding support and Mr Changye Sun for help with Figure S3. 
543

544

545

546

547

548

549

550

551

552

553

554

555

556

557

558

559

560

561

562

563

564

565

566

567

568

569

570

571

572

573

574

575

576

577

578

579

580

581

582

583

584

585

586

587

588
Appleton BA, Wu P, Maloney J, Yin J, Liang WC, Stawicki S, Mortara K, Bowman KK, Elliott JM, Desmarais W, Bazan JF, Bagri A, Tessier-Lavigne M, Koch AW, Wu Y, Watts RJ, and Wiesmann C. 2007. Structural studies of neuropilin/antibody complexes provide insights into semaphorin and VEGF binding. EMBO J 26:4902-4912.

Bruder D, Probst-Kepper M, Westendorf AM, Geffers R, Beissert S, Loser K, von Boehmer H, Buer J, and Hansen W. 2004. Neuropilin-1: a surface marker of regulatory T cells. Eur J Immunol 34:623-630.

Duchesne L, Octeau V, Bearon RN, Beckett A, Prior IA, Lounis B, and Fernig DG. 2012. Transport of fibroblast growth factor 2 in the pericellular matrix is controlled by the spatial distribution of its binding sites in heparan sulfate. PLoS Biol 10:e1001361.

Edwards PR, Gill A, Pollard-Knight DV, Hoare M, Buckle PE, Lowe PA, and Leatherbarrow RJ. 1995. Kinetics of protein-protein interactions at the surface of an optical biosensor. Anal Biochem 231:210-217.

Eswar N, Eramian D, Webb B, Shen MY, and Sali A. 2008. Protein structure modeling with MODELLER. Methods Mol Biol 426:145-159.

Fazili KM, Mir MM, and Qasim MA. 1993. Changes in protein stability upon chemical modification of lysine residues of bovine serum albumin by different reagents. Biochem Mol Biol Int 31:807-816.

Fernig DG. 2001. Optical biosensor techniques to analyze protein-polysaccharide interactions. Methods Mol Biol 171:505-518.

Fuh G, Garcia KC, and de Vos AM. 2000. The interaction of neuropilin-1 with vascular endothelial growth factor and its receptor flt-1. J Biol Chem 275:26690-26695.

Fukasawa M, Matsushita A, and Korc M. 2007. Neuropilin-1 Interacts with Integrin beta1 and Modulates Pancreatic Cancer Cell Growth, Survival and Invasion. Cancer Biol Ther 6:1173-1180.

Giger RJ, Urquhart ER, Gillespie SK, Levengood DV, Ginty DD, and Kolodkin AL. 1998. Neuropilin-2 is a receptor for semaphorin IV: insight into the structural basis of receptor function and specificity. Neuron 21:1079-1092.

Gitay-Goren H, Soker S, Vlodavsky I, and Neufeld G. 1992. The binding of vascular endothelial growth factor to its receptors is dependent on cell surface-associated heparin-like molecules. J Biol Chem 267:6093-6098.

Holm L, and Park J. 2000. DaliLite workbench for protein structure comparison. Bioinformatics 16:566-567.

Karpanen T, Heckman CA, Keskitalo S, Jeltsch M, Ollila H, Neufeld G, Tamagnone L, and Alitalo K. 2006. Functional interaction of VEGF-C and VEGF-D with neuropilin receptors. Faseb Journal 20:1462-1472.

Koyama H, Yamamoto H, and Nishizawa Y. 2007. RAGE and soluble RAGE: potential therapeutic targets for cardiovascular diseases. Mol Med 13:625-635.

Lindahl U, Kusche-Gullberg M, and Kjellen L. 1998. Regulated diversity of heparan sulfate. $J$ Biol Chem 273:24979-24982.

Lu Y, Xiang H, Liu P, Tong RR, Watts RJ, Koch AW, Sandoval WN, Damico LA, Wong WL, and Meng YG. 2009. Identification of circulating neuropilin-1 and dose-dependent elevation following anti-neuropilin-1 antibody administration. MAbs 1:364-369.

Lyon M, Deakin JA, Rahmoune H, Fernig DG, Nakamura T, and Gallagher JT. 1998. Hepatocyte growth factor scatter factor binds with high affinity to dermatan sulfate. Journal of Biological Chemistry 273:271-278. 
589

590

591

592

593

594

595

596

597

598

599

600

601

602

603

604

605

606

607

608

609

610

611

612

613

614

615

616

617

618

619

620

621

622

623

624

625

626

627

628

629

630

631

632

633

634

635
Makinen T, Olofsson B, Karpanen T, Hellman U, Soker S, Klagsbrun M, Eriksson U, and Alitalo K. 1999. Differential binding of vascular endothelial growth factor B splice and proteolytic isoforms to neuropilin-1. J Biol Chem 274:21217-21222.

Mamluk R, Gechtman Z, Kutcher ME, Gasiunas N, Gallagher J, and Klagsbrun M. 2002. Neuropilin-1 binds vascular endothelial growth factor 165, placenta growth factor-2, and heparin via its b1b2 domain. J Biol Chem 277:24818-24825.

Matsushita A, Gotze T, and Korc M. 2007. Hepatocyte growth factor mediated cell invasion in pancreatic cancer cells is dependent on neuropilin-1. Cancer Research 67:10309-10316.

Migdal M, Huppertz B, Tessler S, Comforti A, Shibuya M, Reich R, Baumann H, and Neufeld G. 1998. Neuropilin-1 is a placenta growth factor-2 receptor. J Biol Chem 273:22272-22278.

Molina E, Hermida J, Lopez-Sagaseta J, Puy C, and Montes R. 2008. The functional properties of a truncated form of endothelial cell protein $\mathrm{C}$ receptor generated by alternative splicing. Haematologica 93:878-884.

Murphy KJ, Merry CL, Lyon M, Thompson JE, Roberts IS, and Gallagher JT. 2004. A new model for the domain structure of heparan sulfate based on the novel specificity of K5 lyase. $J$ Biol Chem 279:27239-27245.

Nakagawa Y, Capetillo S, and Jirgensons B. 1972. Effect of chemical modification of lysine residues on the conformation of human immunoglobulin G. J Biol Chem 247:5703-5708.

Nakamura F, Tanaka M, Takahashi T, Kalb RG, and Strittmatter SM. 1998. Neuropilin-1 extracellular domains mediate semaphorin D/III-induced growth cone collapse. Neuron 21:1093-1100.

Narazaki M, Segarra M, and Tosato G. 2008. Sulfated polysaccharides identified as inducers of neuropilin-1 internalization and functional inhibition of VEGF165 and semaphorin3A. Blood 111:4126-4136.

Ori A, Free P, Courty J, Wilkinson MC, and Fernig DG. 2009. Identification of heparin binding sites in proteins by selective labelling. Mol Cell Proteomics 10:2256-2265.

Ori A, Wilkinson MC, and Fernig DG. 2008. The heparanome and regulation of cell function: structures, functions and challenges. Front Biosci 13:4309-4338.

Popplewell JF, Swann MJ, Ahmed Y, Turnbull JE, and Fernig DG. 2009. Fabrication of carbohydrate surfaces by using nonderivatised oligosaccharides, and their application to measuring the assembly of sugar-protein complexes. Chembiochem 10:1218-1226.

Powell AK, Ahmed YA, Yates EA, and Turnbull JE. 2010. Generating heparan sulfate saccharide libraries for glycomics applications. Nat Protoc 5:821-833.

Rahmoune H, Gallagher JT, Rudland PS, and Fernig DG. 1998. Interaction of heparan sulphate from mammary cells with extracellular regulatory proteins. Acidic and fibroblast growth factor: regulation of the activity of bFGF by high and low affinity binding sites in heparan sulphate. J Biol Chem 273:7303-7310.

Rudd TR, Guimond SE, Skidmore MA, Duchesne L, Guerrini M, Torri G, Cosentino C, Brown A, Clarke DT, Turnbull JE, Fernig DG, and Yates EA. 2007. Influence of substitution pattern and cation binding on conformation and activity in heparin derivatives. Glycobiology 17:983-993.

Sadir R, Forest E, and Lortat-Jacob H. 1998. The heparan sulfate binding sequence of interferongamma increased the on rate of the interferon-gamma-interferon-gamma receptor complex formation. J Biol Chem 273:10919-10925.

Sasaki T, Larsson H, Kreuger J, Salmivirta M, Claesson-Welsh L, Lindahl U, Hohenester E, and Timpl R. 1999. Structural basis and potential role of heparin/heparan sulfate binding to the angiogenesis inhibitor endostatin. EMBO J 18:6240-6248. 
636

637

638

639

640

641

642

643

644

645

646

647

648

649

650

651

652

653

654

655

656

657

658

659

660

661

662

663

664

665

666

667

668

669

670

671

672

673

674

675

676

677

678

679

680

681

682

683

684

Shaw JP, Johnson Z, Borlat F, Zwahlen C, Kungl A, Roulin K, Harrenga A, Wells TN, and Proudfoot AE. 2004. The X-ray structure of RANTES: heparin-derived disaccharides allows the rational design of chemokine inhibitors. Structure 12:2081-2093.

Soker S, Fidder H, Neufeld G, and Klagsbrun M. 1996. Characterization of novel vascular endothelial growth factor (VEGF) receptors on tumor cells that bind VEGF165 via its exon 7-encoded domain. J Biol Chem 271:5761-5767.

Soker S, Gollamudi-Payne S, Fidder H, Charmahelli H, and Klagsbrun M. 1997. Inhibition of vascular endothelial growth factor (VEGF)-induced endothelial cell proliferation by a peptide corresponding to the exon 7-encoded domain of VEGF165. J Biol Chem 272:31582-31588.

Soker S, Takashima S, Miao HQ, Neufeld G, and Klagsbrun M. 1998. Neuropilin-1 is expressed by endothelial and tumor cells as an isoform-specific receptor for vascular endothelial growth factor. Cell 92:735-745.

Staton CA, Kumar I, Reed MW, and Brown NJ. 2007. Neuropilins in physiological and pathological angiogenesis. $J$ Pathol 212:237-248.

Swendeman S, Mendelson K, Weskamp G, Horiuchi K, Deutsch U, Scherle P, Hooper A, Rafii S, and Blobel CP. 2008. VEGF-A stimulates ADAM17-dependent shedding of VEGFR2 and crosstalk between VEGFR2 and ERK signaling. Circ Res 103:916-918.

Thompson JD, Higgins DG, and Gibson TJ. 1994. CLUSTAL W: improving the sensitivity of progressive multiple sequence alignment through sequence weighting, position-specific gap penalties and weight matrix choice. Nucleic Acids Res 22:4673-4680.

Torri G, Casu B, Gatti G, Petitou M, Choay J, Jacquinet JC, and Sinay P. 1985. Mono- and bidimensional $500 \mathrm{MHz} 1 \mathrm{H}-\mathrm{NMR}$ spectra of a synthetic pentasaccharide corresponding to the binding sequence of heparin to antithrombin-III: evidence for conformational peculiarity of the sulfated iduronate residue. Biochem Biophys Res Commun 128:134-140.

Uniewicz KA, Cross MJ, and Fernig DG. 2010a. Exogenous recombinant dimeric neuropilin-1 is sufficient to drive angiogenesis. $J$ Biol Chem 286:12-23.

Uniewicz KA, and Fernig DG. 2008. Neuropilins: a versatile partner of extracellular molecules that regulate development and disease. Front Biosci 13:4339-4360.

Uniewicz KA, Ori A, Xu R, Ahmed Y, Wilkinson MC, Fernig DG, and Yates EA. 2010 b. Differential scanning fluorimetry measurement of protein stability changes upon binding to glycosaminoglycans: a screening test for binding specificity. Anal Chem 82:3796-3802.

Valdembri D, Caswell PT, Anderson KI, Schwarz JP, Konig I, Astanina E, Caccavari F, Norman JC, Humphries MJ, Bussolino F, and Serini G. 2009. Neuropilin-1/GIPC1 signaling regulates alpha5beta1 integrin traffic and function in endothelial cells. PLoS Biol 7:e25.

Vander Kooi CW, Jusino MA, Perman B, Neau DB, Bellamy HD, and Leahy DJ. 2007. Structural basis for ligand and heparin binding to neuropilin B domains. Proc Natl Acad Sci U S A 104:6152-6157.

Vanpouille C, Deligny A, Delehedde M, Denys A, Melchior A, Lienard X, Lyon M, Mazurier J, Fernig DG, and Allain F. 2007. The heparin/heparan sulfate sequence that interacts with cyclophilin B contains a 3-O-sulfated N-unsubstituted glucosamine residue. J Biol Chem 282:24416-24429.

West DC, Rees CG, Duchesne L, Patey SJ, Terry CJ, Turnbull JE, Delehedde M, Heegaard CW, Allain F, Vanpouille C, Ron D, and Fernig DG. 2005. Interactions of multiple heparin binding growth factors with neuropilin-1 and potentiation of the activity of fibroblast growth factor-2. J Biol Chem 280:13457-13464.

Whitaker GB, Limberg BJ, and Rosenbaum JS. 2001. Vascular endothelial growth factor receptor-2 and neuropilin-1 form a receptor complex that is responsible for the differential signaling potency of VEGF(165) and VEGF(121). J Biol Chem 276:25520-25531.

PeerJ reviewing PDF | (v2014:03:1891:1:0:ACCEPTED 9 Jun 2014) 
685 Xu D, Suenaga N, Edelmann MJ, Fridman R, Muschel RJ, and Kessler BM. 2008. Novel MMP-9 substrates in cancer cells revealed by a label-free quantitative proteomics approach. Mol Cell Proteomics 7:2215-2228.

688 Xu R, Ori A, Rudd TR, Uniewicz KA, Ahmed YA, Guimond SE, Skidmore MA, Siligardi G, Yates EA, and Fernig DG. 2012. Diversification of the structural determinants of fibroblast

691 287:40061-40073.

692 Yates EA, Santini F, Guerrini M, Naggi A, Torri G, and Casu B. 1996. 1H and 13C NMR spectral 693 assignments of the major sequences of twelve systematically modified heparin derivatives.

694 Carbohydr Res 294:15-27. 


\section{Table 1 (on next page)}

Predominant structures and nomenclature of chemically modified heparins

The letter I stands for iduronate, and A stands for the amino sugar glucosamine. *Numbers refer to the ring position of the carbon atoms. 
1 Table 1 Predominant structures and nomenclature of chemically modified heparins

2 Analogue Predominant repeat

$\begin{array}{lllll}\text { IdoA-2 } & \text { GlcN-6 } & \text { GlcN-2 } & \text { IdoA-3 } & \text { GlcN-3* } \\ \mathrm{SO}_{3}{ }^{-} & \mathrm{SO}_{3}{ }^{-} & \mathrm{SO}_{3}^{-} & \mathrm{OH} & \mathrm{OH} \\ \mathrm{SO}_{3}^{-} & \mathrm{SO}_{3}^{-} & \mathrm{COCH}_{3} & \mathrm{OH} & \mathrm{OH} \\ \mathrm{OH} & \mathrm{SO}_{3}^{-} & \mathrm{SO}_{3}^{-} & \mathrm{OH} & \mathrm{OH} \\ \mathrm{SO}_{3}^{-} & \mathrm{OH} & \mathrm{SO}_{3}^{-} & \mathrm{OH} & \mathrm{OH} \\ \mathrm{OH}^{-} & \mathrm{SO}_{3}^{-} & \mathrm{COCH}_{3} & \mathrm{OH} & \mathrm{OH} \\ \mathrm{SO}_{3}^{-} & \mathrm{OH} & \mathrm{COCH}_{3} & \mathrm{OH} & \mathrm{OH} \\ \mathrm{OH}^{-} & \mathrm{OH} & \mathrm{SO}_{3}^{-} & \mathrm{OH} & \mathrm{OH} \\ \mathrm{OH}^{-} & \mathrm{OH}^{-} & \mathrm{COCH}_{3} & \mathrm{OH} & \mathrm{OH} \\ \mathrm{SO}_{3}^{-} & \mathrm{SO}_{3}^{-} & \mathrm{SO}_{3}^{-} & \mathrm{SO}_{3}^{-} & \mathrm{SO}_{3}^{-}\end{array}$

3 1(heparin) $\mathrm{I}_{2 \mathrm{~S}} \mathrm{~A}^{6 \mathrm{~S}} \mathrm{NS}$

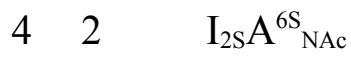

$5 \quad 3 \quad \mathrm{I}_{2 \mathrm{OH}} \mathrm{A}^{6 \mathrm{~S}}{ }_{\mathrm{NS}}$

$64 \quad \mathrm{I}_{2 \mathrm{~S}} \mathrm{~A}^{6 \mathrm{OH}}$

$\begin{array}{lll}7 & 5 & \mathrm{I}_{2 \mathrm{OH}} \mathrm{A}^{6 \mathrm{~S}}{ }_{\mathrm{NAc}}\end{array}$

$8 \quad 6 \quad \mathrm{I}_{2 \mathrm{~S}} \mathrm{~A}_{\mathrm{NAc}}^{6 \mathrm{OH}}$

$97 \quad \mathrm{I}_{2 \mathrm{OH}} \mathrm{A}^{6 \mathrm{OH}}{ }_{\mathrm{NS}}$

aming $\mathrm{SO}_{3}$

$\mathrm{SO}_{3}$

12 The letter I stands for iduronate, and A stands for the amino sugar glucosamine. *Numbers refer to the ring position of the carbon atoms. 


\section{Table 2 (on next page)}

Kinetics and affinity of Fc rNRP-1 binding to a heparin-derivatised surface in an optical biosensor.

$k_{a}$ is the association rate constant, $p$ value is the correlation coefficient of the linear regression through the $k_{o n}$ values, intercept is the $k_{d}$ value obtained from $k_{\text {on }}$ plots,$k_{d}$ is the dissociation rate constant obtained in the dissociation experiments in the presence of competing heparin, and $\mathrm{K}_{\mathrm{d}}$ is the affinity calculated from the ratio of $\mathrm{k}_{\mathrm{d}} / \mathrm{k}_{\mathrm{a}}$. The standard errors (SE) were calculated from five independent association datasets and six independent dissociation datasets and combined for the calculation of $\mathrm{K}_{\mathrm{d}}$. 
1 Table 2 Kinetics and affinity of Fc rNRP-1 binding to a heparin-derivatised surface in an

2 optical biosensor. $k_{a}$ is the association rate constant, $p$ value is the correlation coefficient of the

3 linear regression through the $k_{\text {on }}$ values, intercept is the $k_{d}$ value obtained from $k_{\text {on }}$ plots , $k_{d}$ is the

4 dissociation rate constant obtained in the dissociation experiments in the presence of competing

5 heparin, and $K_{d}$ is the affinity calculated from the ratio of $k_{d} / k_{a}$. The standard errors (SE) were

6 calculated from five independent association datasets and six independent dissociation datasets and

7 combined for the calculation of $\mathrm{K}_{\mathrm{d}}$.

$8 \quad \mathbf{k}_{\mathbf{a}}(\mathrm{Ms})^{-1)}$

$99,800,000 \pm 2,100,000$ p

0.96
Intercept $\left(\mathrm{s}^{-1}\right)$

$0.005 \pm 0.0001$ $\mathbf{k}_{\mathbf{d}}\left(\mathrm{s}^{-1}\right)$

$K_{d}(\mathbf{n M})$
$0.025 \pm 0.0007 \quad 2.5 \pm 0.5$ 


\section{Table 3 (on next page)}

List of peptides identified in the protect and label analysis of the binding sites for heparin in Fc rNRP-1. 
1 Table 3 List of peptides identified in the protect and label analysis of the binding sites for

2 heparin in Fc rNRP-1. The complete list of ions identified by MALDI-Q-TOF mass spectrometery

3 is presented according to the descending intensity of the ions, along with their observed and

4 theoretical masses with appropriate error values (expressed in ppm) and directly linked to the

5 recognised sequences and their respective location within the Fc rNRP-1. The biotinylated lysines

6 are indicated in bold. Assigned spectra are available in the Supplementary data (Fig. S5).

9 experimental calculated (ppm)

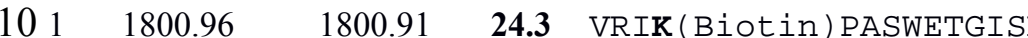

404-417 b1

1121494.76

1494.646476

AGAFR (Acetyl) SDK (Biotin) C (Carbamidomethyl) GGT

$19-30$

a1

$123 \quad 1926.02$

1926.0953 -39.1 DK(Biotin) NISRKPGNVLKTL (Ammonium)

$822-836$

L2

1342024.1

$2024.0481 \quad \mathbf{2 6 . 4}$ TLPPSRDELTK (Biotin) NQVSL

978-993 IgG1 Fc

$145 \quad 2125.14$

2125.0059 63.1 VVVDVSHEDPEVK(Biotin) FNW

890-905 IgG1 Fc

$156 \quad 1452.74$

1452.6358 68.5 AGAFRSDK(Biotin) C (Carbamidomethyl) GGT

$19-30$

a1

$167 \quad 1790.91$

1790.8643 26.1 TVDK(Biotin) SRWQQGNVF

1039-1051 IgG1 Fc

$178 \quad 1381.71 \quad 1381.6603 \quad \mathbf{4 3 . 3} \quad$ NGK(Biotin) EYKCKVS

943-951 IgG1 Fc

778-789 c

$1910 \quad 1811.92$

1811.9069 7.25 SQADENQK (Biotin) GK (Acetyl) VARL

695-708 c

$20112074.06 \quad 2074.0109 \mathbf{2 8} \quad$ MVVGHQGDHWK(Biotin) EGRVL

754-769 c

$2112 \quad 1182.65$

1182.6452

4.05 VRIK(Biotin) PASW

404-411 b1

$2213 \quad 1909 \quad 1909.0688$

-36 DK (Biotin) NISRKPGNVLKTL

822-836 L2

$2314 \quad 1628.7$

1628.6621

23.3 HSYHPSEK(Biotin) CEW

$46-56$

al

$2415 \quad 1364.69$

1364.6337

41.3 NGK (Biotin) EYKCKVS - NH3

943-951 IgG1 Fc 


\section{Figure 1}

Kinetic analysis of Fc rNRP-1 binding to a heparin-derivatised surface in an IAsys optical biosensor.

Data shown are a representative of a set of five independent experiments described in the experimental section. A) Extent of binding of indicated molar amounts of Fc rNRP-1 (arc s). B-F) The distribution of the data points (jagged line) around a one site binding model (horizontal line at 0 arc $s$ ) is shown for each of the concentrations of Fc rNRP-1 used in the binding assay in panel A. B) $0.25 \mathrm{nM}$. C) $0.33 \mathrm{nM}$. D) $0.55 \mathrm{nM}$. E) $0.94 \mathrm{nM}$. F) $1.22 \mathrm{nM}$. G) Linear relationship between the slope of initial rate of association and concentration of Fc rNRP-1. H) Linear relationship between kon, determined from a one-site model, and concentration of Fc rNRP-1. 

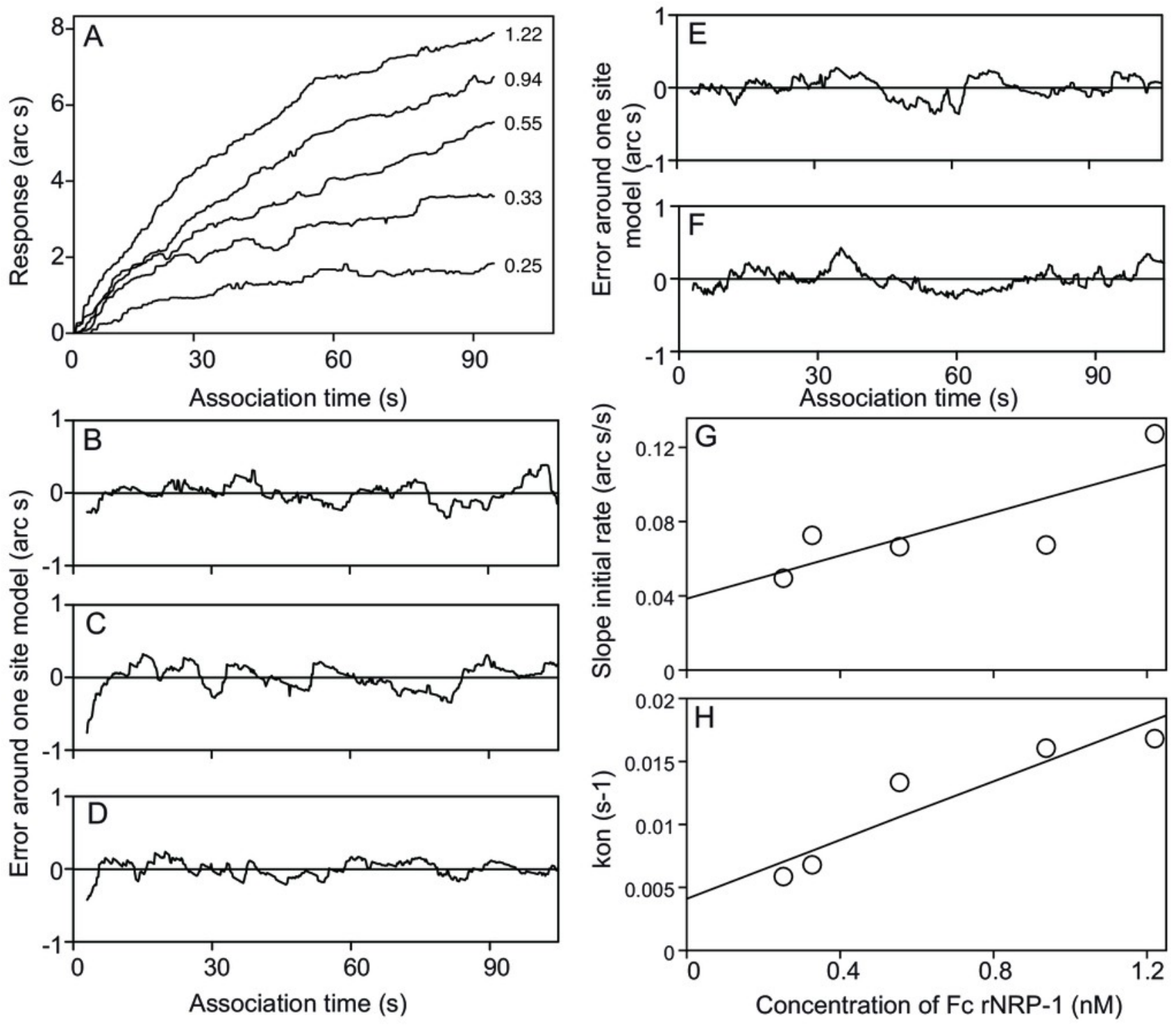


\section{Figure 2}

Competition experiments defining structural requirements of heparin derivatives that enable Fc rNRP-1 binding.

Inhibiting ability of oligosaccharides of selected lengths and modified heparin derivatives on Fc rNRP-1 binding to the heparin derivatised surface was tested, as described in the experimental section. A, C) The relative binding values at each concentration of added sugar competitor were adjusted to $100 \%$ of Fc rNRP-1 binding alone to the immobilised heparin (measured at between 10-40 arc s). In (A) only a selection of curves demonstrating the largest changes in IC50 are shown for clarity, the full set are in Fig. S2). The experiment was performed three times independently (mean $\pm S D)$. B, D) IC50 values of the compounds from the experiments described in panels $A$ and $C$ were calculated from the non-linear curve fit of the respective binding curves and are expressed in (mean $\pm S E \mu \mathrm{g} / \mathrm{mL}$ ). 

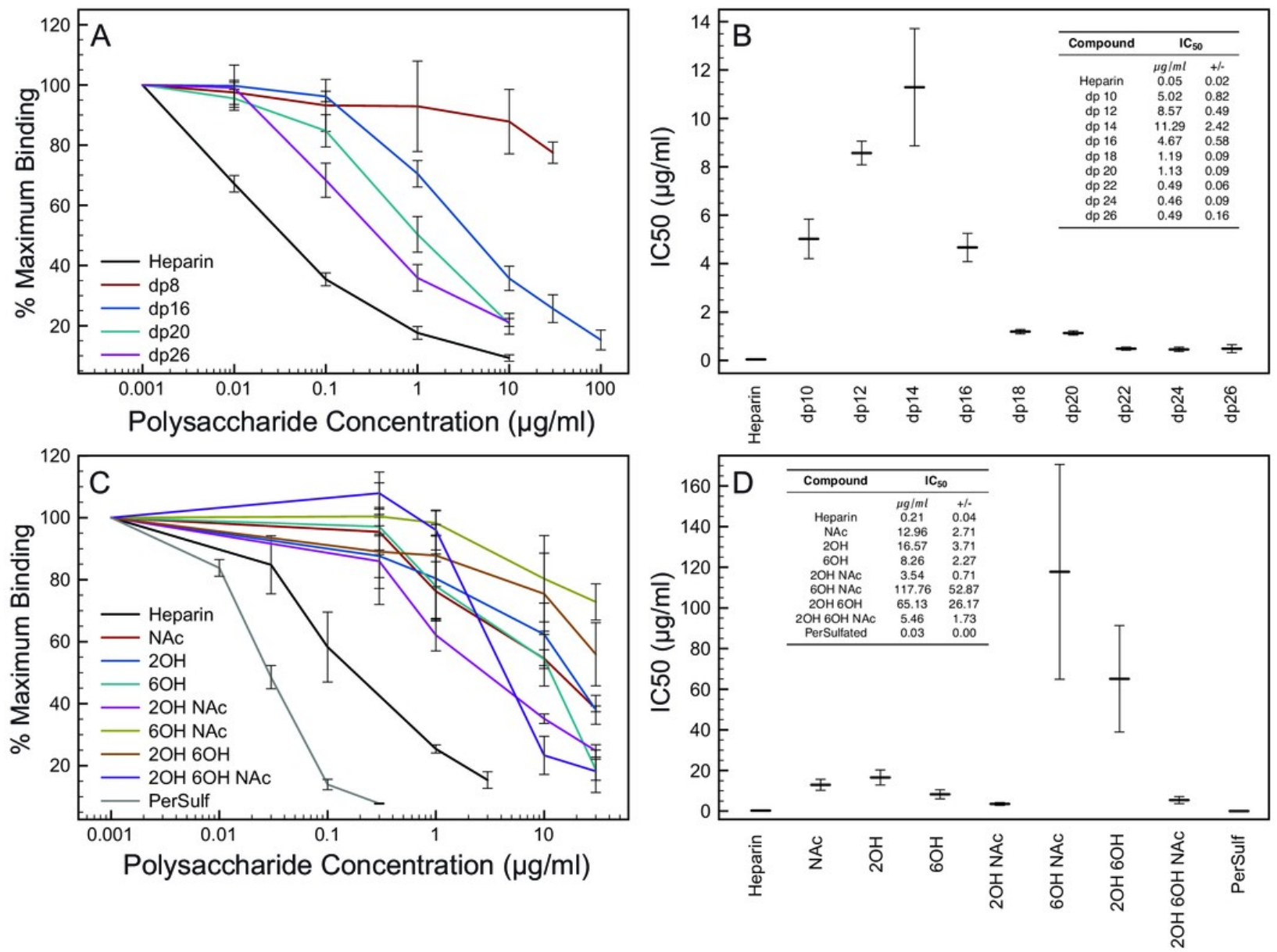


\section{Figure 3}

Identification of the protected regions of Fc rNRP-1 upon interaction with heparin.

A) Represents the steps of analysis of Fc rNRP-1. Lane (LD) corresponds to the sample applied to the heparin column, lane (FT) is the flow through or unbound material after applying the sample three times to the column, lanes (B1 and B2) are the flow through from the two acetylation steps, lane (W1) is the post acetylation wash of the column, elution (E1) is the material eluted from the column with $2 \mathrm{M} \mathrm{NaCl}$, lane (E2) is the same material after biotinylation (E2), and (E3) is the biotinylated material after concentration and buffer exchange. Five \% (v/v) of the total material $(4 \mu \mathrm{g})$ was analysed on SDS-PAGE and silver stained. B) Schematic structure of Fc rNRP-1, where peptides with biotinylated lysines were identified are labelled as black squares. C) Two perspectives of the NRP-1 structure based on in silico modelling (a1-b2 domains) with highlighted residues corresponding to the assigned peptides according to the sequence alignment. In green labelled regions identified by the Protect and Label strategy, in blue the residues identified as heparin-interacting according to (Vander Kooi et al. 2007) . See Fig. S3 for the alignment of NRP-1 sequences corresponding to this structure, with annotated identified peptides. 
A

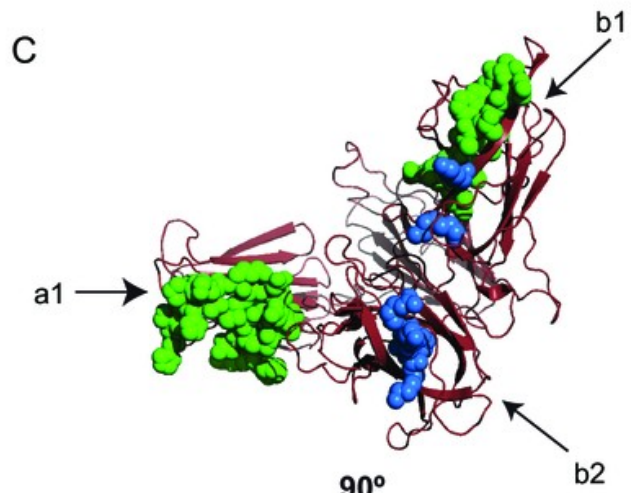

B

\begin{tabular}{|lllllllll} 
LD & FT & B1 & B2 & W1 & E1 & E2 & E3 \\
\hline & & & & & & & & \\
\hline
\end{tabular}

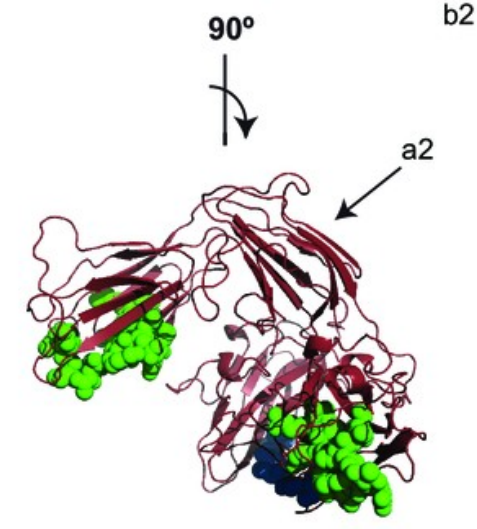




\section{Figure 4}

Comparison of polysaccharide-binding properties of Fc rNRP-1, shNRP-1 and Fc.

Binding of Fc rNRP-1, shNRP-1and Fc to A) a heparin-derivatised surface in an IAsys optical biosensor and to B) a dp 16 derivatised surface in a dual polarisation interferometer.

A

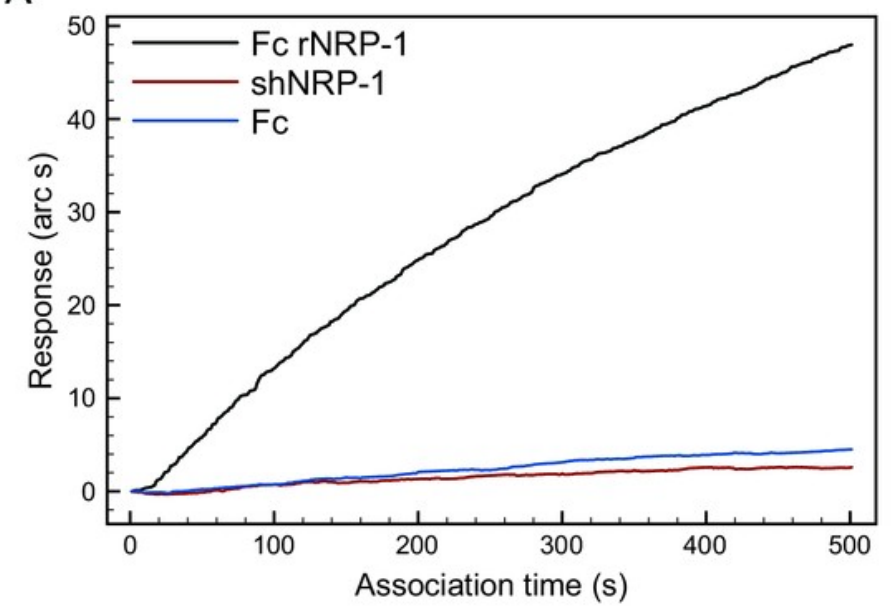

B

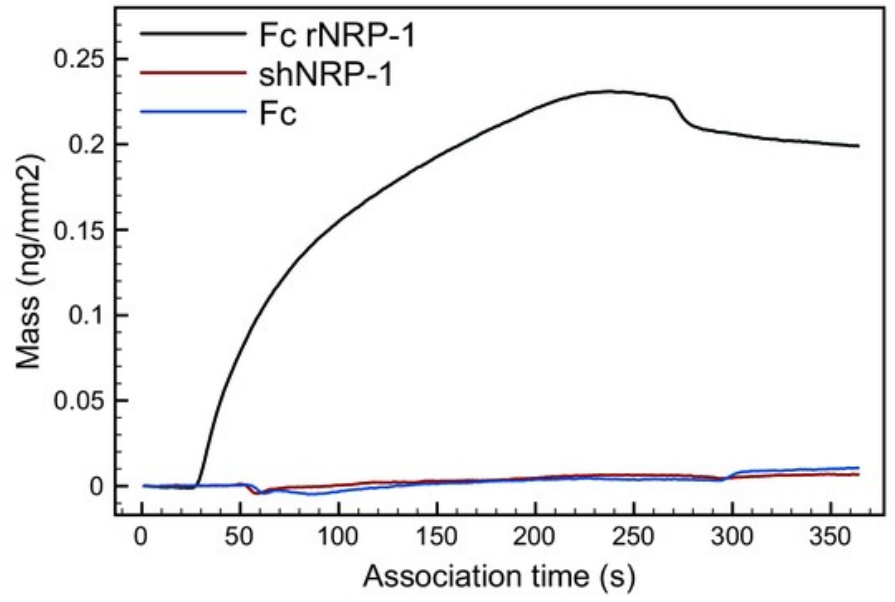




\section{Figure 5}

Sypro stability assay of recombinant NRP-1s in the presence and absence of heparin.

A) Fc rNRP-1, B) shNRP-1 and C) Fc were subjected to denaturation cycle alone or with the indicated amount of heparin in the presence of Sypro Orange dye. The melting curves (mean of three shown) were recorded by the RT-PCR instrument and analysed as described in the Methods. The first derivatives of the melting curves were plotted. D) The melting temperature (Tm) values equal to the maxima of the derivatives from the panels $A, B, C$. 

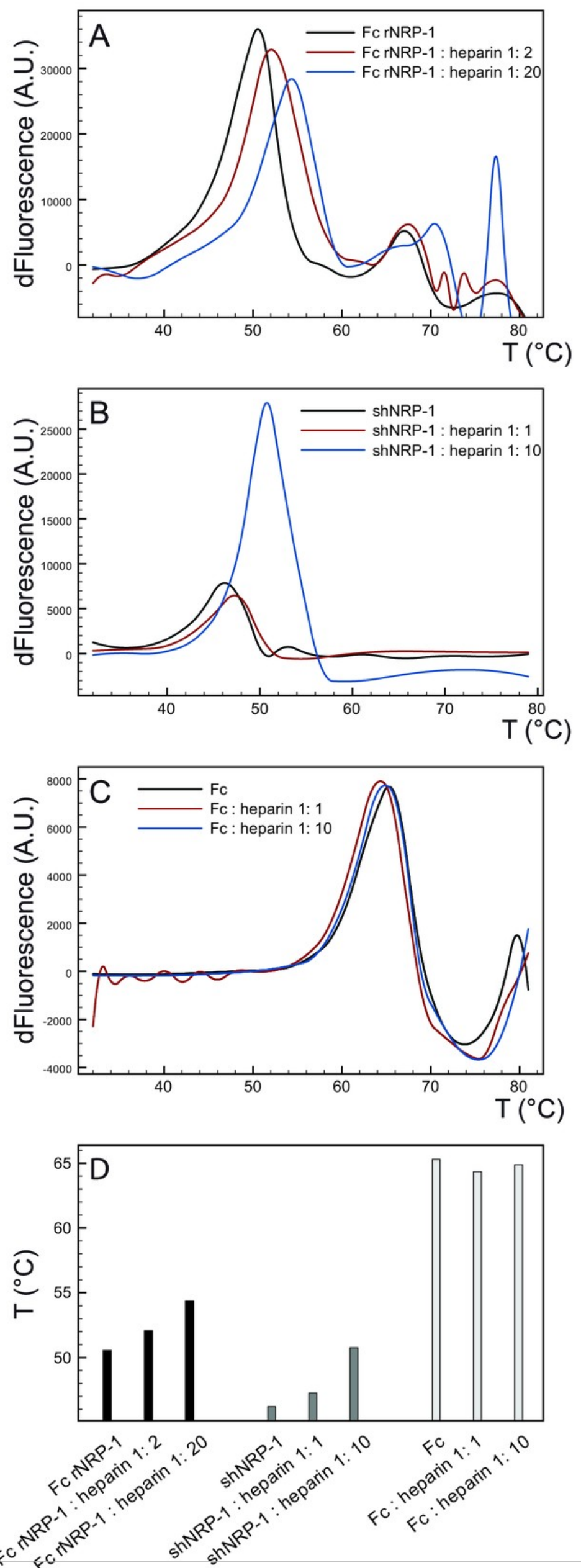